\title{
[voice] AND/VERSUS [spread glottis] IN THE MODIFIED LEIDEN MODEL
}

\author{
DÁNIEL HUBER ${ }^{\mathrm{a}}$ - KATALIN BALOGNÉ BÉRCES ${ }^{\mathrm{b}}$ \\ ${ }^{a}$ Université de Toulouse II \\ Le Mirail, 5 allées Antonio Machado \\ F-31058 Toulouse Cedex 9 \\ France \\ huberd@freemail.hu \\ ${ }^{\text {b} P a ́ z m a ́ n y ~ P e ́ t e r ~ C a t h o l i c ~ U n i v e r s i t y ~}$ \\ Egyetem u. 1. \\ H-2087 Piliscsaba \\ Hungary \\ bbkati@yahoo.com
}

\begin{abstract}
The paper stresses the need to distinguish between two subtypes of binary laryngeal systems, viz. [voice] languages versus [spread glottis] languages ("laryngeal realism"-Honeybone 2005). It criticizes the use of the primes $\mathbf{H}$ and $\mathbf{L}$ for this distinction in Government Phonology, and proposes an alternative representation, based on BackleyTakahashi (1998) and Nasukawa-Backley (2005). This feature geometric model assumes the same set of melodic components for obstruents and sonorants within a system but with a difference in the status of source elements across the language types. Therefore, accompanied by the mechanism of element activation, it is claimed to capture the cross-linguistic observations more adequately.
\end{abstract}

Keywords: laryngeal phonology, Government Phonology, feature geometry, voicing, aspiration

\section{Introduction}

It is more and more widely accepted that the languages on record whose phonological systems contain two series of obstruents either make use of a marked [voice] feature (e.g., Hungarian, Slavic and Romance languages) or marked [spread glottis] (e.g., most Germanic languages, Welsh). The present paper claims that the two systems involve two totally different mechanisms: while in [spread glottis] systems no true laryngeal activity is attested (esp. there is no voice assimilation of obstruents), in [voice] languages (and only in such languages) even (certain) sonorant consonants and vowels can take part in laryngeal assimilation (either actively 
or as an opaque/transparent segment) under restricted conditions. For a privative framework like the Element Theory of Government Phonology (as developed in Kaye et al. 1985; Harris 1994, etc.), this means that (i) distinct phonological primes should be held responsible for the observed facts involving [voice] and [spread glottis]; that (ii) the two representations should suggest two totally different mechanisms; and that (iii) (at least) in [voice] languages, sonorants should have some laryngeal structure. $^{1}$

As Government Phonology's (henceforth, GP) Element Theory, operating with the primes $\mathbf{H}$ and $\mathbf{L}$, fails to capture most of the generalizations above, a new model is proposed. It combines a modified version of Activate Alpha (Backley-Takahashi 1996; 1998) with what we dub the Leiden paper model (Nasukawa-Backley 2005). Our theory expresses [voice] by a single source element, $\mathbf{N}$ (Nasukawa 2005 and references therein), ${ }^{2}$ whereas [spread glottis] is argued not to be true laryngeal activity but rather the manifestation of the element $\mathbf{h}$ (dominant obstruency) in (a kind of) head position. Therefore, in [spread glottis] systems the SOURCE node of the feature geometric tree is totally suppressed, which accounts for the absence of true laryngeal activity in such languages. In addition, the model also explains why the distribution of $/ \mathrm{h} /$ coincides with that of aspiration (since both are only found in foot-initial position, at least in (Standard) English). As a welcome side-effect, the inventory of elements utilized is reduced, which desirably constrains the generative power of the model.

The paper is structured as follows. Section $\mathbf{2}$ introduces the general typology of laryngeal systems and the laryngeal realism approach. Section 3 proposes that laryngeal properties should be expressed by primes responsible for more general properties: aspiration in [spread glottis] languages is a headed expression $\underline{\mathbf{h}}$, and truly voiced obstruents in [voice] languages have headed $\underline{\mathbf{N}}$, where the primes $\mathbf{h}$ and $\mathbf{N}$ express release/ obstruency and nasality/low tone. Section $\mathbf{4}$ discusses the segmental representations we propose and provides analyses. Finally, Section 5 concludes the paper.

${ }^{1}$ A fundamental assumption made in this paper is that both voice and aspiration are to be represented by elements, which is in line with traditional GP principles. Note, however, the alternative claim of GP 2.0 (e.g., Živanović-Pöchtrager 2010) that a number of segmental features, including voicing, are more appropriately modelled as structural configurations.

${ }^{2}$ Nasukawa's conflation of $\mathbf{N}$ and $\mathbf{L}$ in $\mathbf{N}$, which we adopt here, has the same effect as the conflation of $\mathbf{N}$ and $\mathbf{L}$ in $\mathbf{L}$ within Revised Element Theory (see below). 


\section{Laryngeal systems}

Languages differ as to how many series of obstruents they distinguish by some laryngeal specification, such as voicing, aspiration (spread glottis, henceforth [sg]), glottalization (constricted glottis, henceforth [cst gl]). Since in languages with a single series that one series is always voiceless unaspirated unglottalized (e.g., Finnish, Hawaiian, Maori), it is generally accepted that these specifications represent the total absence of laryngeal features. All the more so as this series is present in all other, more complex systems with two, three or more sets of obstruents. Out of these, of particular interest are the binary systems since they reveal the basic mechanisms which are responsible for the marked feature values, whose combinations also produce the more complex systems. The attested twoway systems are enumerated and exemplified in chart (1) (inspired by Iverson-Salmons 1995, 383 and 2003, 45).

(1) Two-way laryngeal contrasts in obstruents ${ }^{3}$

\begin{tabular}{|c|c|c|c|c|}
\hline Examples & $\mathrm{p} \sim \mathrm{b}$ & $\mathrm{b}$ & $\mathrm{p}^{\mathrm{h}}$ & $p^{\prime}$ \\
\hline English, ${ }^{4}$ German, Welsh & ] & & {$[\mathrm{sg}]$} & \\
\hline Romance, Slavic & ] & [voice] & & \\
\hline K'ekchi (Q'eqchi'), Mam & [ ] & & & [cst gl] \\
\hline
\end{tabular}

The present discussion is only concerned with French-type so-called [voice] languages and English-type so-called [sg] languages ${ }^{5}$ with [cst gl] languages left open for future research. We follow the tradition that has been described as "the narrow interpretation of [voice]" or "laryngeal realism" (cf. Honeybone 2005), and claim that a distinction must be drawn between languages in which the laryngeal system is based on non-spontaneous voicing, i.e., voicing in the strict sense ([b] vs. [p]), and languages in which the obstruents traditionally analyzed as voiced versus voiceless actually phonetically contrast in negative versus positive

${ }^{3}$ In more complex laryngeal systems [voice], [sg] and [cst gl] combine in various ways, e.g., [voice]-cum-[sg] is realized as a voiced aspirate $\left(/ \mathrm{b}^{\mathrm{h}} /\right)$ as in Hindi, cf. Iverson-Salmons $(1995,383)$, etc.

4 Throughout the paper, "English" refers to all present-day accents of English except for certain varieties of Scottish English/Scots, cf. Wells (1982, 409-12); Iverson-Salmons (1999, 22-3).

${ }^{5}$ For the typological terminology cf. Iverson-Salmons (1995, and subsequent publications), etc.

Acta Linguistica Hungarica 57, 2010 
VOT lag ([b] vs. $\left[\mathrm{p}^{\mathrm{h}}\right]$ —recall the classical lenis vs. fortis distinction). ${ }^{6}$ We are convinced that the difference between these language types does not simply lie in the phonetic manifestation of an underlying voiceless vs. voiced distinction, as has been commonly held since the beginnings of Generative Phonology, but is of phonological relevance as it has serious consequences for the whole obstruent system. Namely, while in [sg] systems no true laryngeal activity is attested (esp. there is no voice assimilation of obstruents), in [voice] languages voice assimilation is a very strong tendency (if not a rule). We interpret this as evidence that source features are only active in [voice] languages, which also means that aspiration is the result of a totally different mechanism.

\section{GP's Element Theory: problems and solutions}

Earlier GP analyses of laryngeal processes suffer from shortcomings which result from either ignoring some of the related phenomena or failing to establish the [voice]-[sg] typological dichotomy. Harris (1994, 133-8 and 194-225), for instance, offers an $\mathbf{L} / \mathbf{H}$ analysis concentrating on English /t/-allophones in his theory of Licensing Inheritance. Although he uses the two laryngeal elements in a way that reflects the typological differences between languages (see (2)), he does not consider two related phenomena, the behaviour of fortis fricatives (esp. /s/) and sonorant devoicing in aspirated + sonorant clusters (i.e., data like the ones in (3) below). In addition, his analysis fails to reflect our claim above that [voice] and [sg] should be given totally different representations.

(2) Harris' (1994) system

\begin{tabular}{lccc}
\hline & Element & English & French \\
\cline { 2 - 4 } Voiced & $\mathbf{L}$ & - & {$[\mathrm{b}]$} \\
Neutral & - & $\underline{b} a y$ & {$[\mathrm{p}]$} \\
Voiceless aspirated & $\mathbf{H}$ & $\underline{p} a y$ & - \\
\hline
\end{tabular}

\footnotetext{
${ }^{6}$ Notice in the chart in (1) that the phonetic symbols for voiceless unaspirated and devoiced lenis are coreferential and therefore interchangeable $(\mathrm{p} \sim \mathrm{b})$. This is supported by phonetic evidence, cf. Iverson-Salmons (2008) and references therein.
} 
Others do not even observe language typology. For example, Brockhaus (1999) provides a Licensing Inheritance account of German final devoicing (e.g., blieb [bli:p] '(I/he/she/it) stayed' versus bliebe [bli:bə] '(I/he/she/it) would stay'), but fails to establish German as a spread glottis system without active [voice] and claims that "final devoicing consists in the depletion of a-licensing potential, resulting in the withdrawal of an alicense from the source element L" (op.cit., 198).

There are other problems with "classical" $\mathbf{L}$ and $\mathbf{H}$, too. The element $\mathbf{L}$ has been the target of fierce criticism for a long time. For example, it is a kind of misfit as, unlike the other elements, it does not obey the Autonomous Interpretation Hypothesis, according to which primes of phonological representations should all enjoy "stand-alone phonetic interpretability" (Harris-Lindsey 1995, 34) (noted in Szigetvári 1996; Sóskuthy 2008, etc.). The connection between voice and nasality as well as the redundancy of systems using separate primes for the two are also well-known and resulted in GP's Revised Element Theory (Kaye 1995, etc.) claiming that nasality is low tone, therefore the element $\mathbf{L}$ should represent low tone, nasality and voicing. Alternatively, $\mathbf{L}$ can be replaced by $\mathbf{N}$, as is done in Nasukawa (2005) so that [voice] and nasality are expressed by $\mathbf{N}$ in such a way that it is head in (truly) voiced obstruents but non-head in nasals. In this paper we opt for this latter solution, although the choice has no immediate consequences for the present argument and the two alternatives may turn out to be merely notational variants.

The element $\mathbf{H}$ is not without problems, either. First, voicelessness is unmarked in obstruents, therefore no element is needed to represent it, and it is not the same as aspiration. Second, [sg] does not behave as a simple element; e.g., unlike [voice], it never spreads in obstruent clusters. Third, like $\mathbf{L}, \mathbf{H}$ is also involved in a redundancy, viz. the one concerning $/ \mathrm{h} /$, which is ambiguously analyzable as the interpretation of either $\mathbf{H}$ or $\mathbf{h}$.

Our reaction to these problems is drastic: we propose to "throw away" both $\mathbf{L}$ and $\mathbf{H}$. We have mentioned above that $\mathbf{L}$ can be replaced by $\mathbf{N}$ to represent distinctive [voice]. Now let us turn to [sg]. An important observation to be made is that aspiration in [sg] languages is a property of all fortis consonants, that is, it is coextensive with fortisness. In English, for instance, not only the fortis plosives are aspirated but in fact all the phenomena that are traditionally associated with "voiceless" plosive aspiration also characterize fortis fricatives. In the words in (3), the underlined sonorants undergo (partial) devoicing in the same way (3a-b), 
or remain voiced due to the well-known $s$-effect (actually caused by all fortis fricatives- $(3 \mathrm{c})){ }^{7}$

(3) Aspiration phenomena in English ${ }^{8}$

(a) peat, seat, sheep, feet, cheap

(b) prim, slit, shrink, fleet

(c) spear, sphere, after, spray

In addition, in [sg] languages lenis obstruents take on passive voicing between sonorants, that is, there is an obvious connection between lenis and sonorant "voicing". From the above we infer that fortis consonants are more obstruent-like than lenis ones, i.e., aspiration is dominant obstruency. It follows, then, that [sg] has to be represented by the element $\mathbf{h}$ dominating the expression, that is, in the role of head.

Therefore, our proposal here is that aspiration in [sg] languages is a headed expression $\underline{\mathbf{h}}$, and truly voiced obstruents in [voice] languages have headed $\mathbf{N}$. The non-headed expressions, $\mathbf{h}$ and $\mathbf{N}$, stand for oral release and nasality, respectively, as shown in (4).

(4) Representations in (a) [sg] and (b) [voice] languages

(a) aspirated unaspirated released

$[\underline{\mathbf{h}}] \quad[\mathrm{l} \quad[\mathbf{h}]$

(b) voiced voiceless nasals

$[\underline{\mathbf{N}}] \quad[\mathrm{l}] \quad[\mathbf{N}]$

In what follows, we sketch out the components of the theoretical framework in which these basic representations will be used to analyze the data introduced above.

7 The claim that fricatives fall under the same rubric as plosives is in fact the "null hypothesis" in Honeybone (2005); also cf. his analysis of Southern English Fricative Voicing, in which fricatives are treated as having the same [sg] specification. Iverson and Salmons (1995, and other publications) argue for the same.

${ }^{8}$ Notice that the devoicing effect of fortis obstruents on following sonorants is not an automatic phonetic process stemming from obstruent voicelessness: (i) it is only found in [sg] languages, and (ii) it is not driven by simple string-adjacency but is heavily constrained by morpho-syntax (e.g., ap [r] on vs. pop [r] ock; I s[1] ip vs. ice [1]ip; the same applies to the s-effect: $m i s[\mathrm{t}]$ ake vs. $\left.m i s\left[\mathrm{t}^{\mathrm{h}}\right] i m e\right)$. 


\section{Theoretical framework}

\subsection{Activate $\alpha$ (Backley-Takahashi 1996; 1998)}

Backley and Takahashi $(1996 ; 1998)$ worked out a mechanism, originally to represent vocalic harmony processes, that accounts for the licensing of elements in a structure in terms of alignment. It assumes all resonance elements $\{\mathbf{I}, \mathbf{U}, \mathbf{A}\}$ to be present in all positions. It also respects the strict Structure Preservation Principle by claiming head-switching illicit as a possible operation. They introduce the notion of tier complement (an additional tier in the feature geometry complementing the one it is adjoined to; henceforth abbreviated to [comp]) and element activation (a lexical instruction to activate an element lying dormant on its tier or on the tier complement).

(5) Backley - Takahashi $(1996 ; 1998)$

$\begin{array}{llcc}\text { tier complement } & > & {[\mathbf{I}]^{[\text {comp }]}} & \\ \text { melodic tier } & > & \mid \mathbf{I}]^{\prime} \\ \text { aperture tier } & > & {[\mathbf{A}]} & {[\mathbf{A}]} \\ & & {[\mathrm{e}]} & {[\varepsilon]}\end{array}$

ATR harmony, then, is not analyzed as headedness harmony, in which case the (non-structure-preserving) operation of head-switching is needed, but as the effect of the Activate [comp] instruction. This way, Element Theory's "headedness" is translated as the activation of [comp]. The affiliation of [comp] is lexically determined, but its activation is not necessarily so, and it may or may not be triggered during the phonological computation.

Although Backley and Takahashi analyze vowel systems, there is nothing in principle that would talk us out of treating consonants in a like manner.

\subsection{The Leiden paper model (Nasukawa-Backley 2005)}

Nasukawa and Backley (2005), in what we informally dub the 'Leiden paper model', develop a uniform representation for vowels and consonants. They assume that all elements are present in all positions in direct continuation of Backley-Takahashi $(1996 ; 1998)$. What is new in the Leiden 
model is that elements are grouped into EDGE, SOURCE, RESONANCE and FUNDAMENTAL sets, as given in (6).
(6) EDGE
$\{\mathbf{P}, \mathbf{h}\}$
RESONANCE
$\{\mathbf{I}, \mathbf{U}\}$
SOURCE $\{\mathbf{L}, \mathbf{H}\}$
FUNDAMENTAL $\{\mathbf{A}\}$

They are grouped into two larger sets, resonance and edge sets. The resonance set $\{\mathbf{A} ; \mathbf{I}, \mathbf{U}\}$ comprises the RESONANCE and FUNDAMENTAL sets, and the edge set $\{\mathbf{P}, \mathbf{h} ; \mathbf{L}, \mathbf{H}\}$ comprises the EDGE and SOURCE sets. The supergroups edge and resonance stand in a dominance relationship, and there is a dominance relationship among their members too. In a consonant expression, within the edge group the EDGE elements $\{\mathbf{P}, \mathbf{h}\}$ dominate SOURCE $\{\mathbf{H}, \mathbf{L}\}$, while within the resonance group, the RESONANCE elements $\{\mathbf{I}, \mathbf{U}\}$ dominate the Fundamental element $\{\mathbf{A}\}$. Not only can both groups be present in the melody of all segments (depending on language type - cf. tier/group rejection/suppression to be introduced below), vowels and consonants alike, but they can also be empty. The difference between vowels and consonants falls out of the difference in dominance relations: in consonants, edge elements dominate resonance elements, in vowels it is the other way round, see (7).

(7) Nasukawa and Backley's Leiden model for (a) consonants and (b) vowels
(a) EDGE
$\{\mathbf{h}, ?\}=\mathrm{X}$
SOURCE
$\{\mathbf{L}, \mathbf{H}\}$
(b) FUNDAMENTAL
$\{\mathbf{A}\}=\mathrm{X}$
RESONANCE
$\{\mathbf{I}, \mathbf{U}\}$
RESONANCE
$\{\mathbf{I}, \mathbf{U}\}$
FUNDAMENTAL
$\{\mathbf{A}\}$
SOURCE
$\{\mathbf{L}, \mathbf{H}\}$
EDGE $\quad\{\mathbf{h}, \mathbf{P}\}$

\subsection{The modified Leiden model}

In the following analyses we use the combination of Activate $\boldsymbol{\alpha}$ and a modified version of the Leiden paper model. There is a crucial point on which the proposal in this paper differs significantly from the original Leiden model. Namely, we assume but one element in SOURCE: N, standing for nasality and voicing. Two pieces of argument can be offered in defence of this choice. The first is that the present analysis does not make recourse to $\mathbf{H}$ at all. This is a welcome step, since, by reducing the total number 
of primes available in the model, it constrains its generative power. ${ }^{9}$ The second is that suppressing $\mathbf{H}$ from SOURCE, the content of the dependent sets in consonants, SOURCE and FUNDAMENTAL, are brought into line with each other: each of them contains only one element, $\mathbf{N}$ and $\mathbf{A}$, respectively. Note that it is the dependent sets in consonants which only contain one element each - as they are dominated sets, no wonder they are able to maintain a smaller number of primes. With these considerations in mind, the following modification of the Leiden model is proposed:

(8) The modified Leiden model for (a) consonants and (b) vowels
(a) EDGE
$\{\mathbf{h}, \mathbf{P}\}=\mathrm{X}$
SOURCE

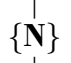
RESONANCE
$\{\mathbf{N}\}$
FUNDAMENTAL
$\{\mathbf{I}, \mathbf{U}\}$
$\{\mathbf{A}\}$
(b) FUNDAMENTAL
$\{\mathbf{A}\}=\mathrm{X}$
RESONANCE
$\{\mathbf{I}, \mathbf{U}\}$
SOURCE
$\{\mathbf{N}\}$
EDGE
$\{\mathbf{h}, \mathbf{P}\}$

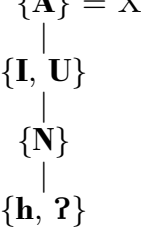

Incorporating the tier complements, the representation in (9) states the maximal structure consonants can have. ${ }^{10}$

(9) The maximal structure of consonants

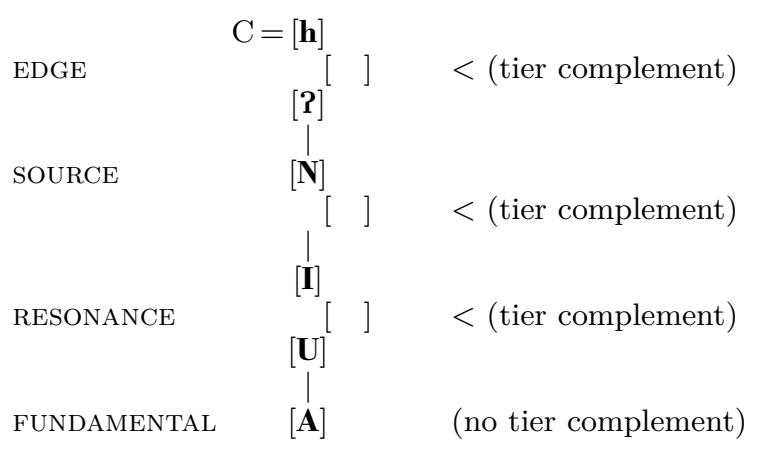

${ }^{9}$ Clearly, though, the definitive loss of $\mathbf{H}$ needs additional arguments, especially as far as tonal contours, in which this element used to play a crucial role, are concerned.

10 To constrain the high potentiality of tier complements, it is suggested in HuberBalogné Bérces (2009) that obstruents lacking the laryngeal specification will also lack any element that could have an active tier [comp]. In other words, resonance elements are never so prominent as to allow a tier complement in a consonant. 
This is a general universal template; language-specific templates may be much more restricted, for instance, by tier conflation (familiar from the description of vowel inventories) or element/tier "rejection" or "suppression" (see below). One important property of the structure above is that there is no pre-defined dominance relationship within the groups of elements, rather they are unordered as for dominance. This is reflected in the absence of association lines between $\mathbf{I}$ and $\mathbf{U}$ as well as between $\mathbf{P}$ and $\mathbf{h}$. Specifically, it cannot be said that $\mathbf{I}$ dominates $\mathbf{U}$ within RESONANCE, and similarly there are no dominance relations between the EDGE elements ? and $\mathbf{h}$. Notice, however, that sets can have two elements at most. ${ }^{11}$

In this framework the difference between [sg] and [voice] languages is the following. In [voice] systems the maximal structure (9) is utilized in such a way that voiced obstruents contain the element $\mathbf{N}$ in SOURCE [comp], in traditional terms, they are $\mathbf{N}$-headed expressions. In [sg] systems, however, SOURCE is totally inactive, i.e., there are no truly laryngeal features in segments. We call this element/tier "rejection" or "suppression", and we signal it by leaving the whole tier out of the representations. Fortis consonants are underlying aspirates, ${ }^{12}$ they have $\mathbf{h}$ in EDGE [comp]. In (10), we give example representations.

(10) Examples in the modified Leiden model

(a) Representations in a [voice] language

$\begin{array}{llllllll} & {[\mathrm{p}]} & {[\mathrm{f}]} & {[\mathrm{m}]} & {[\mathrm{b}]} & {[\mathrm{v}]} & {[\beta] \text { or }[\mathrm{v}]} & {[\mathrm{w}]} \\ \operatorname{EDGE} & {[\mathbf{h}]} & {[\mathbf{h}]} & {[]} & {[\mathbf{h}]} & {[\mathbf{h}]} & {[]} & {[]} \\ & {[\mathbf{P}]} & {[]} & {[\mathbf{2}]} & {[\mathbf{2}]} & {[]} & {[]} & {[]} \\ \text { SOURCE } & {[]} & {[]} & {[\mathbf{N}]} & {[\mathbf{N}]} & {[\mathbf{N}]} & {[\mathbf{N}]} & {[]} \\ \quad \text { comp } & {[]} & {[]} & {[]} & {[\mathbf{N}]} & {[\mathbf{N}]} & {[\mathbf{N}]} & {[]} \\ \text { RESONANCE } & {[\mathbf{U}]} & {[\mathbf{U}]} & {[\mathbf{U}]} & {[\mathbf{U}]} & {[\mathbf{U}]} & {[\mathbf{U}]} & {[\mathbf{U}]}\end{array}$

11 The view, and its implications, that empty RESONANCE is coronality and empty FUNDAMENTAL is velarity is further discussed in Huber (2008). The issue of whether FUNDAMENTAL has a tier complement in consonants or not is beyond the scope of, and irrelevant to, the present discussion. It is suspected that FUNDAMENTAL has no tier complement in consonants. Whether this applies to vowels, too, is left open here.

12 Cf. Iverson-Salmons (1995); Nasukawa-Backley (2005), etc. 
(b) Representations in a [sg] language

\begin{tabular}{|c|c|c|c|c|c|}
\hline & {$\left[\mathrm{p}^{\mathrm{h}}\right]$} & {$\left[\mathrm{f}^{\mathrm{h}}\right]$} & {$[\mathrm{p}]=[\mathrm{b}]$} & {$[\mathrm{f}]=[\mathrm{v}]$} & {$[\mathrm{m}]$} \\
\hline EDGE & {$[\mathbf{h}]$} & {$[\mathbf{h}]$} & {$[\mathbf{h}]$} & {$[\mathbf{h}]$} & \\
\hline comp & {$[\mathbf{h}]$} & {$[\mathbf{h}$} & & {[} & [?] \\
\hline RESONANCE & {$[\mathbf{U}]$} & {$[\mathbf{U}]$} & {$[\mathbf{U}]$} & {$[\mathbf{U}]$} & {$[\mathbf{U}]$} \\
\hline
\end{tabular}

\subsection{Analysis}

In the following two sections we outline how the theoretical framework just introduced can be used to describe the observations mentioned above.

\subsection{1. [spread glottis] languages}

In [sg] languages sOuRCE is "suppressed", that is, not present in representations. This explains why there is no true laryngeal activity, no voice assimilation in such systems: there is nothing to assimilate. Aspiration, on the other hand, taking the form of a "dominant" $\mathbf{h}$ element, i.e., $\mathbf{h}$ in [comp], is part of the underlying representation of fortis obstruents (therefore when it surfaces it is not the result of a feature-adding fortition process as traditionally analyzed) but it is allowed to realize phonetically only when it is licensed to do so. Licensing is used here as introduced in the theory of Coda Mirror (Ségéral-Scheer 1999). This means that $\mathbf{h}$ in [comp] will manifest itself in strong phonological positions, typically word-initially, before stressed vowels, and as $\mathrm{C}_{2}$ in heterosyllabic clusters, but will remain unlicensed and dormant in weak positions, e.g., as $\mathrm{C}_{1}$ in heterosyllabic clusters. We formulate this licensing mechanism as the instruction Activate h, which can only apply in licensed positions. Once $\mathbf{h}$ is activated in obstruents, however, it is able in turn to activate itself in the next (non-empty) consonant or vowel, where it is interpreted as devoicing. Bear in mind that this devoicing is caused by fortis plosives and fricatives alike since fortis fricatives have a dominant $\mathbf{h}$ element, too, which explains their ability to devoice sonorants analogously to aspiration. Aspiration, then, can be regarded as a kind of agreement (very similar to harmony) in which $\mathbf{h}$ is "transmitted" to the next segment.

In addition, the sound $/ \mathrm{h} /$ is now unambiguously analyzable as the stand-alone interpretation of h, also subject to Activate h. This explains why the distribution of aspiration and the segment /h/ coincide (at least in (Standard) English and (Standard) German). 
In (11) we provide illustrations for plosive and fricative aspiration causing sonorant devoicing, from English. ${ }^{13}$

(11) Aspiration in English

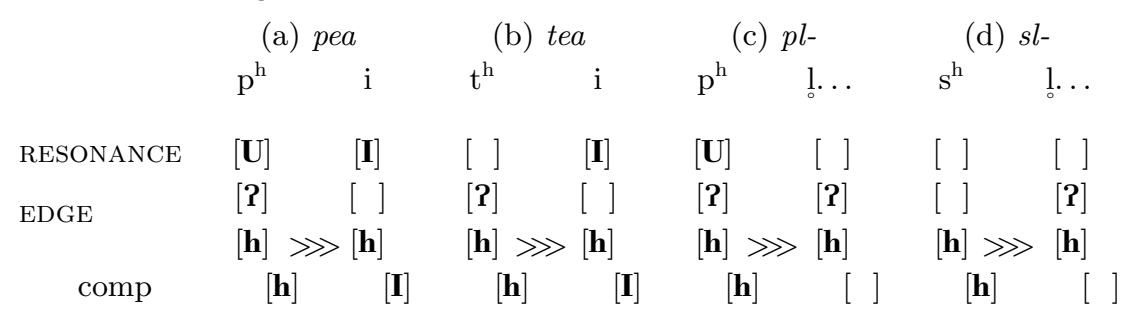

\subsection{2. [voice] languages}

In [voice] systems like Hungarian, the underlying representations contain $\mathbf{N}$ in SOURCE [comp] in voiced obstruents, while voiceless consonants are laryngeally unspecified, that is, they do not have $\mathbf{N}$ at all. Voice assimilation is the result of the instruction Activate $\mathbf{N}$ in licensed position, where licensing comes from a following non-empty vowel. Since we treat all clusters as bogus (Strict CV/VC Phonology aka CVCV Phonology, Lowenstamm 1996, etc.), i.e., as $\mathrm{C}_{1} \mathrm{vC}_{2}$, where $\mathrm{v}=$ empty nucleus, $\mathrm{C}_{1}$ will always be unlicensed while $\mathrm{C}_{2}$ is licensed by the following pronounced vowel. ${ }^{14}$ This derives regressive voice assimilation (see (12), overleaf).

In (12a) $\mathbf{N}$ is licensed in [g], which activates $\mathbf{N}$ in the preceding, otherwise unlicensed obstruent, in such a way that it automatically opens a tier complement and becomes the "head" of the expression. In (12b), on the other hand, $\mathbf{N}$ fails to be interpreted in /b/ because the empty vowel between $/ \mathrm{b} /$ and $/ \mathrm{k} /$ cannot license it. Therefore it remains unactivated, which renders the consonant voiceless.

\section{Conclusion}

We have argued, taking the strict "laryngeal realism" stance, that twoway obstruent systems that involve [voice] have radically different representations from two-way systems involving [spread glottis] as is evidenced

13 As the difference between consonants and vowels would overcomplicate the representation, the dominance relations in the feature set hierarchy are ignored. See (8) above.

${ }^{14}$ Word-final empty nuclei are also able to license Activate N, cf. Hu mos- $d[-3 \mathrm{~d}]$ 'wash-2sg.def'. We judge this to be their special property. 
(12) Voice assimilation in Hungarian ${ }^{15}$

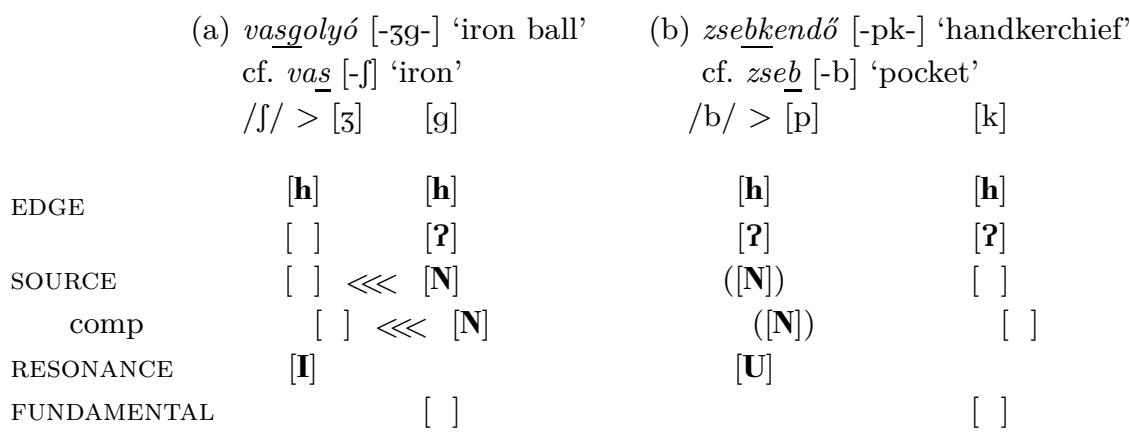

by the two totally different mechanisms these systems imply: while in [spread glottis] systems no true laryngeal activity is attested and there is no voice assimilation of obstruents, in [voice] languages (and only in such languages) there is true laryngeal activity which may even involve (certain) sonorant consonants and vowels under restricted conditions. It has been argued that in GP this pattern is best captured not by assuming primes that specifically encode voicing and aspiration, but by using elements that have a more general application. We take these to be $\mathbf{N}$ and $\underline{\mathbf{h}}$ for voice and aspiration, respectively. Although space limitations prevent us from providing a detailed demonstration of the model and discussing more complicated phenomena (e.g., the $s$-effect in aspiration languages, or the analysis of "final devoicing" in both language types), we claim that, as long as voice and aspiration are conceived as melodic/elemental rather than structural properties, the proposed representations account for all known laryngeal processes more adequately.

\section{References}

Backley, Phillip - Toyomi Takahashi 1996. Activate $\alpha$ : Harmony without spreading. In: UCL Working Papers in Linguistics 8:487-518.

Backley, Phillip-Toyomi Takahashi 1998. Element activation. In: Eugeniusz Cyran (ed.): Structure and interpretation. Studies in phonology (PASE Studies \& Monographs 4), 13-40. Wydawnictwo Folium, Lublin.

Brockhaus, Wiebke 1999. The syllable in German: Exploring an alternative. In: Harry van der Hulst-Nancy A. Ritter (eds): The syllable: Views and facts, 169-218. Mouton de Gruyter, Berlin \& New York.

${ }^{15}$ In the present discussion of Hungarian voice assimilation, we ignore the problematic cases of $/ \mathrm{h} /$ and $/ \mathrm{v} /$.

Acta Linguistica Hungarica 57, 2010 
[voice] AND/VERSUS [spread glottis] IN THE MODIFIED LEIDEN MODEL 457

Durand, Jacques - Francis Katamba (eds) 1995. Frontiers of phonology: Atoms, structures, derivations. Longman, Harlow.

Harris, John 1994. English sound structure. Blackwell, Oxford \& Cambridge MA.

Harris, John-Geoff Lindsey 1995. The elements of phonological representation. In: Durand-Katamba (1995, 34-79).

Honeybone, Patrick 2005. Diachronic evidence in segmental phonology: The case of obstruent laryngeal specifications. In: Marc van Oostendorp - Jeroen van de Weijer (eds): The internal organization of phonological segments, 319-54. Mouton de Gruyter, Berlin \& New York.

Huber, Dániel 2008. Velars and processes: Their representation in phonological theory. Doctoral dissertation, Eötvös Loránd University (ELTE), Budapest.

Huber, Dániel-Katalin Balogné Bérces 2009. Aspiration and voice in Government Phonology. Ms. (www.bbkati.eoldal.hu/cikkek/papers/huber-bbk)

Iverson, Gregory K. - Joseph C. Salmons 1995. Aspiration and laryngeal representation in Germanic. In: Phonology 12:369-96.

Iverson, Gregory K. - Joseph C. Salmons 1999. Glottal spreading bias in Germanic. In: Linguistische Berichte 178:135-51.

Iverson, Gregory K.- Joseph C. Salmons 2003. Laryngeal enhancement in early Germanic. In: Phonology $20: 43-74$.

Iverson, Gregory K.- Joseph C. Salmons 2008. Germanic aspiration: Phonetic enhancement and language contact. In: Sprachwissenschaft 33:257-78.

Kaye, Jonathan 1995. Derivations and interfaces. In: Durand-Katamba (1995, 289$332)$.

Kaye, Jonathan - Jean Lowenstamm - Jean-Roger Vergnaud 1985. The internal structure of phonological representations: A theory of charm and government. In: Phonology Yearbook 2:305-28.

Lowenstamm, Jean 1996. CV as the only syllable type. In: Jacques Durand-Bernard Laks (eds): Current trends in phonology. Models and methods, 419-41. European Studies Research Institute, University of Salford Publications, Salford.

Nasukawa, Kuniya 2005. A unified approach to nasality and voicing. Mouton de Gruyter, Berlin \& New York.

Nasukawa, Kuniya-Phillip Backley 2005. Dependency relations in Element Theory. In: Leiden Papers in Linguistics $2: 77-93$.

Ségéral, Philippe-Tobias Scheer 1999. The Coda Mirror. Ms. Université de Paris 7 and Université de Nice.

Sóskuthy, Márton 2008. Voicing and the skeleton. In: Sylvia Blaho-Camelia Constantinescu-Erik Schoorlemmer (eds): Proceedings of ConSOLE XV, 247-70. Student Organisation of Linguistics in Europe, Leiden.

Szigetvári, Péter 1996. Laryngeal contrasts and problematic representations. In: The Even Yearbook 2:97-110.

Wells, John Christopher 1982. Accents of English 1-3. Cambridge University Press, Cambridge.

Živanović, Sašo-Markus Alexander Pöchtrager 2010. GP 2.0 and Putonghua too. In: Acta Linguistica Hungarica $57: 357-80$. 